\title{
How Specific Are Risk Factors for Headache in Adolescents? Results from a Cross-sectional Study in Germany
}

\author{
Steffi Lehmann ${ }^{1}$ Astrid Milde-Busch ${ }^{1}$ Andreas Straube ${ }^{2}$ Ruediger von Kries ${ }^{1}$ Florian Heinen ${ }^{3}$ \\ ${ }^{1}$ Institute of Social Paediatrics and Adolescent Medicine, Medical \\ Faculty of the Ludwig-Maximilians-University Munich, Munich, \\ Bavaria, Germany \\ ${ }^{2}$ Department of Neurology, University of Munich, Munich, Germany \\ Address for correspondence and reprint requests Steffi Lehmann, \\ MEd, MPH, Medical Faculty, Institute of Social Paediatrics and \\ Adolescent Medicine, Heiglhofstr. 63 München 81377, Germany \\ (e-mail: steffi.lehmann@med.uni-muenchen.de).
}

${ }^{3}$ Department of Paediatric Neurology and Developmental Medicine, Hauner Children's Hospital, University of Munich, Munich, Germany

Neuropediatrics 2013;44:46-54.

\begin{abstract}
Background The identified preventable risk factors for primary headache in adolescents are smoking; consumption of coffee or alcoholic mixed drinks; physical inactivity; muscle pain in the head, neck, or shoulder region; and chronic stress.

Objective To investigate the interrelation of headache with other health complaints and the specificity of the above-mentioned risk factors for headache in adolescents.

Methods A total of 1,260 students (grades 10 and 11) filled in questionnaires on headache, dietary, and lifestyle factors. The type of headache and health complaints such as dizziness, abdominal pain, musculoskeletal pains, symptoms of possible fatigue syndrome, and psychic complaints were assessed.

Results Isolated headache was found in $18 \%$ of the headache sufferers; most frequently isolated tension-type headache (78.2\%). Only among adolescents with a combination of headache (mainly migraine) and other health complaints, significant

Keywords

- isolated headache

- adolescents

- pain

- health complaints

- risk factors

- specificity associations for almost all analyzed risk factors were found. The strength of the associations with the considered risk factors was very similar in all three analyzed strata except for considerably lower odds ratios for isolated headache.

Conclusion All analyzed risk factors are nonspecific for headache in adolescents because they also increase the risk for other health complaints. Interventions, therefore, should consider a holistic approach focusing not only on headache but also on a broader spectrum of health complaints.
\end{abstract}

\section{Introduction}

Primary headache is a very common and relevant health problem all over the world causing enormous human, psychosocial, and economic burden for the sufferers and the society. ${ }^{1}$ In Germany, the estimates for the headache prevalence among adolescents range between 48 and $83 \% .^{2-7}$ The prevalence of headache increases with age ${ }^{8-11}$

received

September 14, 2012

accepted after revision

December 12, 2012

published online

January 10, 2013 and is higher in females ${ }^{12-15}$ and adolescents aiming at higher education. ${ }^{3}$ Several epidemiological studies stated that headache sufferers also report additional associated symptoms, conditions, and comorbidities such as abdominal pain, ${ }^{4,15-18}$ musculoskeletal (back, neck, or shoulder) pains, ${ }^{4,15,18}$ vertigo, ${ }^{16,19}$ sleep problems, ${ }^{15,17,19,20}$ tiredness, $^{19}$ or psychosocial symptoms (e.g., anxiety, depression, anger). ${ }^{16,17,20}$ In a previous survey on adolescents' headache, several other health
Issue Theme Headaches in Childhood and Adolescence; Guest Editor, Florian Heinen, MD. (c) 2013 Georg Thieme Verlog KG
Stuttgart · New York
DOI http://dx.doi.org/ 10.1055/s-0032-1333432. ISSN 0174-304X. 
complaints in adolescents was also measured, therefore providing the opportunity to assess the interrelation of headache with other health complaints and the specificity of the risk factors for headache in adolescents.

Several risk factors for headache were identified in epidemiological studies in children and adolescents. ${ }^{4,10,21-27}$ Some of them such as genetic and climate factors are not influenceable. Others such as dietary and lifestyle factors can be targeted by interventions suggesting that the burden of headache might be reduced by successful preventive intervention. In a data set on German adolescents, ${ }^{28}$ we recently identified several dietary and lifestyle factors associated with headache in grammar school students that might be amenable to interventions: smoking, consumption of coffee or alcoholic cocktails, and low physical activity. In addition, it has been shown that muscle pain and chronic stress are related to headache in adolescents. ${ }^{29,30}$

It is unclear, however, whether the identified risk factors are specific for headache in adolescents or not. Unspecific risk factors might be an indication that headache has to be considered as a prominent symptom within a complex of health complaints related to, for example, stress and other risk factors.

There are some individuals exhibiting only headache and no other health complaints. Now the question is whether the spectrum of risk factors is disjunctive between these adolescents with isolated headache and adolescents with headache in combination with other health complaints. This seems to be important with respect to our concept of headache. Is headache the tip of the iceberg in adolescents with a mixture of health complaints as suggested from the observation that most individuals with headache present additional health complaints as well? This concept would be further substantiated by identical risk factors. These questions were not addressed in previous analyses of the data set. The present analyses link other health complaints with headache and the potentially risk factors. In addition, the strength of these associations is compared with them between isolated headache and the risk factors to answer the main research question: Are the identified potentially preventable risk factors for headache in adolescents specific?

\section{Patients and Methods}

\section{Study Sample and Procedure}

The population-based cross-sectional study was performed on students from grades 10 and 11 (aged between 14 and 20 years) from public grammar schools in Munich, Germany. All principals from the 37 public grammar schools in Munich were informed about the study and were invited to participate. Eleven principals declared consent that their students from grades 10 and 11 can be invited for participation in the study and they named a contact person (teacher, school psychologist) at their school. The students and their parents were informed about the study by a letter distributed by the contact person. The parents signed an informed consent allowing their child to participate in the study. Contact persons collected these consent forms and stored them at school. For data safety, study members did neither obtain any individual information on the potential participants nor gain insight into the informed consent forms.

The data were collected by means of a self-administered questionnaire during a regular school hour in class between October 2008 and February 2009. On the day of data collection, contact persons or class teachers identified those students whose parents had given written consent. Consent of the participants themselves was assumed when they handed over the completed questionnaires to the study members. Off all students present on the respective day of data collection, $94.8 \%$ agreed to fill in the questionnaire. The exact sampling procedure is described elsewhere in detail. ${ }^{29}$ The approval for the presented cross-sectional study was obtained from the Data Safety Officer and the Ethic Committee (082-08) from the Medical Faculty of the Ludwig-Maximilians-University Munich and the Bavarian Ministry for Education and Culture.

\section{Instruments}

Headache classification. Items of the headache questionnaire were based on the German translation of the International Classification of Headache Disorders-2nd edition (ICHD-II). ${ }^{31}$ A positive answer to the screening question "Did you have headache during the last six months?" identified adolescents with or without headache. Students with any headache answered further questions regarding frequency, duration, characteristics, and symptoms of their headache. On the basis of the criteria of ICHD-II, a classification of pure migraine (including the subtypes migraine with or without aura, chronic migraine, probable migraine, and probable chronic migraine) and pure tension-type headache (TTH, including the subtypes infrequent episodic TTH, frequent episodic TTH, chronic TTH, probable infrequent episodic TTH, probable frequent episodic TTH, and probable chronic TTH) were given. A double diagnosis of combined migraine and TTH could arise in subjects fulfilling the diagnostic criteria for both probable (chronic) migraine and probable (episodic or chronic) TTH that require compliance with all but one of the respective diagnostic criteria for migraine or TTH. All other subjects with headache who did not match any of these classifications for primary headache were considered to have miscellaneous headache $(\mathrm{MH})$. The headache-type $\mathrm{MH}$ was excluded from further analyses because of too few cases $(n=55)$. Headache sufferers who did not report any other health complaint (i.e., musculoskeletal pains, psychic complaints, possible fatigue syndrome, dizziness or abdominal pain, as defined below) were classified as isolated headache.

Health complaints. Health complaints were assessed with the complaints list from von Zerssen (Die Beschwerden-Liste, 20 items) ${ }^{32}$ and seven additional items (back, neck, or shoulder and abdominal pain, feelings of pressure or bloating in the abdomen, heartburn or acid regurgitation, menstrual molimen, and other pains). For each of the 27 items, all students were asked to rate their personal severity on a 4-point Likert scale (severe, moderate, scarcely, not at all). For analyses, the dimensions were dichotomized (severe/moderate vs. scarcely/ not at all). The definition of relevant health complaint groups was guided by two principles: (1) confinement to the most common health complaints and (2) consistency within 
greater categories. The health complaints that were most frequently described by the participants were summarized on the basis of medical or psychological coherence into three different complaints groups: musculoskeletal pains, possible fatigue syndrome, and psychic complaints. The group musculoskeletal pains is based on the complaints list questions pertaining to back pain and/or neck or shoulder pain. The group psychic complaints is based on a positive answer to at least one of the questions to brooding and/or inner restlessness. In the case that the participants reported at least three of the following five single symptoms, they were classified as possible fatigue syndrome: feeling of weakness, fatigue, irritability, excessively high sleep requirement, and insomnia. Dizziness and abdominal pain were separately assessed in the complaints list. For further analyses, the health complaints, respectively complaints groups, were further summarized as any health complaints (at least one of the following: dizziness, abdominal pain, musculoskeletal pains, possible fatigue syndrome, and psychic complaints), excluding any headache.

Risk factors. The questionnaire covered as possible risk factors items on dietary habits and lifestyle factors that were classified and dichotomized as follows: coffee (none vs. any: $<1$ cup per week/ $<1$ cup per day $/ \leq 1$ cups per day), alcohol (none: nothing vs. any: $<1$ glass per month $/<1$ glass per week/ $\leq 1$ glasses per day), smoking (no vs. yes: seldom/once per week/several times per week/daily), and physical inactivity (How often do you do sport outside school?-yes: never/ less than once a week vs. no: once a week/2/3/4/5/6/7 times a week). Muscle pain was assessed by the yes-no question: "Do you feel pain in the head, neck, or shoulder?" For the measurement of chronic stress experience, the 12-item Screening Scale of Chronic Stress (SSCS) was used which is part of the self-report instrument Trier Inventory of Chronic Stress (57 items in total). ${ }^{33}$ The SSCS incorporates items from five different dimensions: chronic worries, school and social overload, pressure to succeed, and lack of social recognition. For each item, the frequency of personal experience within the past 3 months had to be indicated on a 5-point Likert scale from 0 (never) to 4 (very often). For the performed analyses, the results from the SSCS were dichotomized and used as the variable chronic stress (above average SSCS score vs. normal/ below average) (see also the studies by Milde-Busch et $\mathrm{al}^{29}$ and Schulz et $\mathrm{al}^{33}$ ).

Further questions concerned potentially confounding variables such as sex (female and male), grade (10th and 11th), and socioeconomic variables. The following socioeconomic variables were considered: students own income (nothing vs. any), monthly pocket money (dichotomized as 50 Euro per month or less vs. more than 50 Euro per month), and questions on parents' employment status, which were categorized into full-time versus not full-time, separately for student's mother and father.

\section{Statistical Analyses}

The prevalence of headache types, health complaints, and risk factors was calculated. The analyses stratified for type of headache and sex were conducted. Differences and associations between categorical variables were tested by using $\chi^{2}$ tests and $p$ values less than 0.05 were considered to indicate a significant difference. To analyze the strength of associations of possible risk factors with headache, separate logistic regression models, adjusted for sex, grade, and socioeconomic variables as potential confounders, were performed for the following outcomes: isolated headache, any of the five health complaints, and any headache in combination with any of the five health complaints (each comparing against no complaints). The following six potential risk factors functioned as independent variables: smoking; consumption of coffee or alcoholic mixed drinks; physical inactivity; muscle pain in the head, neck, or shoulder region; and chronic stress. To account for multiple testing, Bonferroni correction was applied to tests of the logistic regression models, separately for each of the six potential risk factors (adjusted significance level $\alpha: 0.05 / 6=0.0083$ ). All $p$ values less than 0.0083 were considered to indicate a significant association. The adjusted odds ratios (OR) with 95\% confidence intervals $(\mathrm{CI})$ were estimated. For all analyses, SAS software package (version 9.2, SAS Institute Inc. Cary, North Carolina, United States) was used.

\section{Results}

\section{Characteristics of the Study Population}

Altogether, 1,818 adolescents were invited for participation in the study. At the day of data collection, 1,504 adolescents (82.7\%) were present at school. The causes for absence were suffering from seasonal infectious diseases or participating in school activities somewhere else. Overall, 1,426 of these students (94.8\%) actually filled in the questionnaire. Because of missing values in relevant socioeconomic variables, 166 questionnaires had to be excluded from analyses. Students with excluded questionnaires did not significantly differ from remaining subjects with respect to the headache prevalence. $^{29}$ Finally, questionnaires from 1,260 students from the grades 10 and 11 (age range between 14 and 20 years, mean age $16 \pm 0.9$ years) entered the statistical analyses. Of the included participants, $56.4 \%$ were female and $43.6 \%$ male; $51.7 \%$ attended the 10 th grade and $48.3 \%$ the 11 th grade. Grade was used as an equivalent for age (mean age of those in 10th grade 15.6 years and of those in 11 th grade 16.7 years). Details on invited students and participation rates have been described elsewhere in detail. ${ }^{29}$

\section{Prevalence of Headache Types and Other Health Complaints}

In total, 1,047 students (83.1\%) suffered from any headache at least once during the last 6 months. From all headache sufferers, $12.3 \%$ were classified as pure migraine, $58.6 \%$ as pure $\mathrm{TTH}, 23.8 \%$ as any migraine plus any $\mathrm{TTH}$, and $5.3 \%$ as any $\mathrm{MH}$. The frequency of any of these headache types was higher in female adolescents than in male adolescents $(p<0.001$, $\mathrm{MH}: p=0.035$ ).

The distribution of other health complaints is illustrated in -Table 1. Almost all of the reported health complaints were significantly more frequently reported by female than 
Table 1 Prevalence of health complaints, stratified by sex

\begin{tabular}{|c|c|c|c|c|c|c|c|}
\hline \multirow[t]{3}{*}{ Health complaints } & \multirow{2}{*}{\multicolumn{2}{|c|}{ Total }} & \multicolumn{4}{|c|}{ Sex } & \multirow[t]{3}{*}{$p^{a}$} \\
\hline & & & \multicolumn{2}{|c|}{ Female } & \multicolumn{2}{|c|}{ Male } & \\
\hline & $n$ & $\%$ & $n$ & $\%$ & $n$ & $\%$ & \\
\hline \multicolumn{8}{|l|}{ Single health complaints } \\
\hline Any headache & 1,047 & 83.1 & 590 & 88.2 & 457 & 77.3 & $<0.001$ \\
\hline Back pain ${ }^{b}$ & 601 & 47.7 & 403 & 60.2 & 198 & 33.5 & $<0.001$ \\
\hline Excessively high sleep requirement ${ }^{c}$ & 574 & 45.6 & 351 & 52.5 & 223 & 37.7 & $<0.001$ \\
\hline Neck or shoulder pain ${ }^{b}$ & 567 & 45.0 & 394 & 58.9 & 173 & 29.3 & $<0.001$ \\
\hline Inner restlessness $^{\mathrm{d}}$ & 453 & 36.0 & 316 & 47.2 & 137 & 23.2 & $<0.001$ \\
\hline Irritability ${ }^{c}$ & 439 & 34.8 & 298 & 44.5 & 141 & 23.9 & $<0.001$ \\
\hline Fatigue $^{c}$ & 417 & 33.1 & 293 & 43.8 & 124 & 21.0 & $<0.001$ \\
\hline Feeling of weakness ${ }^{c}$ & 388 & 30.8 & 286 & 42.8 & 102 & 17.3 & $<0.001$ \\
\hline Brooding $^{\mathrm{d}}$ & 381 & 30.2 & 263 & 39.3 & 118 & 20.0 & $<0.001$ \\
\hline Dizziness & 342 & 27.1 & 257 & 38.4 & 85 & 14.4 & $<0.001$ \\
\hline Stings, pain, or dragging in the breast & 317 & 25.2 & 231 & 34.5 & 86 & 14.6 & $<0.001$ \\
\hline Insomniac & 307 & 24.4 & 204 & 30.5 & 103 & 17.4 & $<0.001$ \\
\hline Abdominal pain & 306 & 24.3 & 241 & 36.0 & 65 & 11.0 & $<0.001$ \\
\hline Feelings of heaviness or tiredness of the legs & 288 & 22.9 & 190 & 28.4 & 98 & 16.6 & $<0.001$ \\
\hline Restlessness of the legs & 256 & 20.3 & 145 & 21.7 & 111 & 18.8 & 0.209 \\
\hline Intolerance to cold & 256 & 20.3 & 180 & 26.9 & 76 & 12.9 & $<0.001$ \\
\hline Heavy sweating & 219 & 17.4 & 109 & 16.3 & 110 & 18.6 & 0.295 \\
\hline Feelings of pressure or bloating in the abdomen & 206 & 16.3 & 159 & 23.8 & 47 & 8.0 & $<0.001$ \\
\hline Nausea & 199 & 15.8 & 145 & 21.7 & 54 & 9.1 & $<0.001$ \\
\hline Tremble & 178 & 14.1 & 128 & 19.1 & 50 & 8.5 & $<0.001$ \\
\hline Intolerance to heat & 175 & 13.9 & 109 & 16.3 & 66 & 11.2 & 0.008 \\
\hline Dyspnea & 148 & 11.7 & 111 & 16.6 & 37 & 6.3 & $<0.001$ \\
\hline Feelings of a lump, narrowness or choke in the throat & 119 & 9.4 & 72 & 10.8 & 47 & 8.0 & 0.085 \\
\hline Heartburn or acid regurgitation & 111 & 8.8 & 54 & 8.1 & 57 & 9.6 & 0.326 \\
\hline Difficulties swallowing & 107 & 8.5 & 59 & 8.8 & 48 & 8.1 & 0.637 \\
\hline Weight reduction & 69 & 5.5 & 45 & 6.7 & 24 & 4.1 & 0.038 \\
\hline Other pains & 38 & 3.0 & 243 & 3.4 & 15 & 2.5 & 0.976 \\
\hline Menstrual molimen (only girls) & 361 & 54.0 & 361 & 54.0 & - & - & - \\
\hline \multicolumn{8}{|l|}{ Health complaints groups } \\
\hline Musculoskeletal pains & 736 & 58.4 & 482 & 72.0 & 254 & 43.0 & $<0.001$ \\
\hline Psychic complaints & 603 & 47.9 & 403 & 60.2 & 200 & 33.8 & $<0.001$ \\
\hline Possible fatigue syndrome & 349 & 27.7 & 82 & 12.3 & 267 & 45.2 & $<0.001$ \\
\hline Dizziness & 342 & 27.1 & 257 & 38.4 & 85 & 14.4 & $<0.001$ \\
\hline Abdominal pain & 306 & 24.3 & 241 & 36.0 & 65 & 11.0 & $<0.001$ \\
\hline $\begin{array}{l}\text { No complaints (no headache and none of the } \\
\text { analyzed health complaints) }\end{array}$ & 93 & 7.38 & 19 & 2.8 & 74 & 12.5 & $<0.001$ \\
\hline Total study population ${ }^{\mathrm{e}}$ & 1,260 & 100.0 & 669 & 100.0 & 591 & 100.0 & - \\
\hline
\end{tabular}

${ }^{\mathrm{a}}$ Results from $\chi^{2}$ test. Significant results are marked in bold $(p<0.05)$.

bBack, neck, or shoulder pains are summarized to the health complaints group "Musculoskeletal pains."

'Excessively high sleep requirement, irritability, fatigue, feeling of weakness, and insomnia are summarized to the health complaints group "possible fatigue syndrome."

"Inner restlessness and brooding are summarized to the health complaints group "Psychic complaints."

eAll percent values in each column do not add up to $100.0 \%$ because combinations of several health complaints are possible. 
by male adolescents $(p<0.001)$. The most common health complaints pertained to musculoskeletal pains (58.4\%), psychic complaints (47.9\%), possible fatigue syndrome (27.7\%), dizziness $(27.1 \%)$, and abdominal pain (24.3\%). In total, there were 93 of all 1,260 students (7.4\%) neither reporting headache nor any of the above-mentioned health complaints at all. The male to female ratio among these was $4: 1(p<0.001)$.

Among the 1,047 adolescents with headache 188 (18.0\%) did not report any other health complaints and thus were assigned to the category isolated headache (-Table 2). Most of these individuals with isolated headache had pure TTH (78.2\%).

The most frequently associated complaints with headache were musculoskeletal pains (57.0 to $76.0 \%$ ) and psychic complaints ( 45.6 to $69.0 \%$ ). Identical patterns of combinations were noticeable for combinations of other health complaints for pure migraine and for migraine and TTH; whereas, pure TTH was less often associated with other health complains (-Table 2).

\section{Frequency of Possible Risk Factors}

The consumption of alcoholic mixed drinks (61.3\%) and coffee (55.2\%) was widespread (-Table 3). In total, $26.6 \%$ of the students stated they smoke and $24.4 \%$ to be physically inactive. For $20.4 \%$ of all students, an SSCS score above average was found and $47.6 \%$ described to have muscle pain in the head, neck, or shoulder region. More female than male adolescents reported drinking coffee; to be physically inactive; to have an above-average SSCS score; and to have muscle pain in the head, neck, or shoulder region $(p<0.001)$. No differences for the sex variable were found for the consumption of alcoholic mixed drinks and smoking. Significantly more students with headache than students without headache reported to consume coffee or alcoholic mixed drinks, to have an above-average SSCS score, and to have muscle pain $(p \leq 0.002)$. Significantly more students with health complaints (excluding headache) than students without health complaints at all stated physical inactivity, chronic stress, and muscle pain $(p \leq 0.002)$ ( - Table 3 ). The detailed distribution of dietary and lifestyle factors in the study population and their associations with the adjustment variables sex, grade, and socioeconomic variables can be found elsewhere. ${ }^{28}$ The prevalence of the analyzed six risk factors among adolescents with any headache was higher than in those reporting any of the five other health complaints alone ( $\mathbf{- T a b l e ~} \mathbf{3}$ ).

\section{Associations between the Possible Risk Factors and Headache and Other Health Complaints}

Only among the adolescents with a combination of any headache and other health complaints were significant associations observed for all assessed risk factors except for the consumption of alcoholic mixed drinks. The strength of the associations with the considered risk factors was very similar in all three analyzed strata (isolated headache, any of the five health complaints, and the combination of both) with the exception of considerably lower OR for the associations between isolated headache and chronic stress or muscle pain (-Table 4). Because most cases of isolated headache were adolescents with TTH, we hypothesized that the absence of an association was related to TTH. Indeed, no significant associations to neither of the potential risk factors could be seen for isolated TTH (data not shown).

\section{Discussion}

\section{Key Findings}

Only $18 \%$ of the individuals with headache reported isolated headache. The identified risk factors, smoking; consumption of coffee or alcoholic mixed drinks; physical inactivity; chronic stress; and muscle pain in the head, neck, or shoulder, were not specific for headache in adolescents but appeared to be related to a broader array of other health complaints in adolescents. The apparently low or absent associations of chronic stress and muscle pain to isolated headache are likely to be a reflection of the fact that isolated $\mathrm{TTH}$, which accounted for most of the cases with isolated headache, is apparently not at all or not strongly associated with muscle pain and chronic stress.

Table 2 Relative frequency of isolated headache and headache in combination with other health complaints, stratified for type of headache

\begin{tabular}{|l|l|l|l|l|}
\hline & $\begin{array}{l}\text { Any headache } \\
N=1,047 \\
(100.0 \%)^{\mathbf{a}}\end{array}$ & $\begin{array}{l}\text { Pure migraine } \\
N=129 \\
(100.0 \%)^{\mathbf{a}}\end{array}$ & $\begin{array}{l}\text { Migraine }+ \text { TTH } \\
\mathbf{2}=49 \\
(\mathbf{1 0 0 . 0 \%})^{\mathbf{a}}\end{array}$ & $\begin{array}{l}\text { Pure TTH } \\
N=614 \\
(100.0 \%)^{\mathbf{a}}\end{array}$ \\
\hline Isolated headache + no other health complaints $(N=281), n(\%)$ & $188(18.0)$ & $9(7.0)$ & $20(8.0)$ & $147(23.9)$ \\
\hline Headache + dizziness $(N=490), n(\%)^{\mathbf{b}}$ & $312(29.8)$ & $66(51.2)$ & $106(42.6)$ & $132(21.5)$ \\
\hline Headache + abdominal pain $(N=463), n(\%)^{\mathbf{b}}$ & $281(26.8)$ & $48(37.2)$ & $85(34.1)$ & $140(22.8)$ \\
\hline Headache + musculoskeletal pains $(N=798), n(\%)^{\mathbf{b}}$ & $663(63.3)$ & $98(76.0)$ & $184(73.9)$ & $350(57.0)$ \\
\hline Headache + possible fatigue syndrome $(N=490), n(\%)^{\mathbf{b}}$ & $315(30.1)$ & $60(46.5)$ & $109(43.8)$ & $134(21.8)$ \\
\hline Headache + psychic complaints, $(N=697), n(\%)^{\mathbf{b}}$ & $546(52.1)$ & $89(69.0)$ & $150(60.2)$ & $280(45.6)$ \\
\hline
\end{tabular}

Abbreviations: $\mathrm{MH}$, miscellaneous headache; $\mathrm{TTH}$, tension type headache.

${ }^{a}$ All percent values in each column do not add up to $100.0 \%$ because combinations of several health complaints are possible.

"The values of "Pure migraine," "Migraine + TTH," and "Pure TTH" do not add up to the values of "Any headache" because the headache-type MH had been excluded because of too small numbers $(n=55)$. 


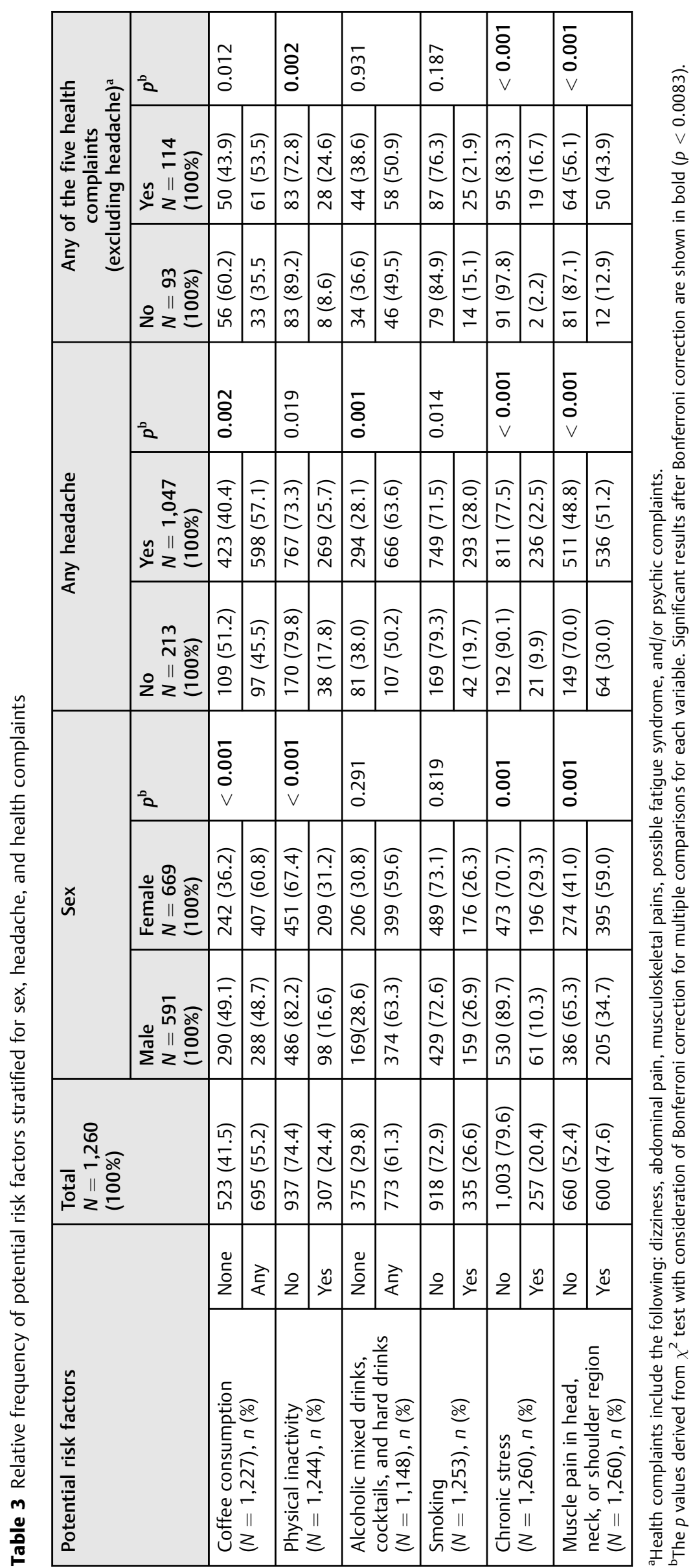


Table 4 Adjusted odds ratio, 95\% Cl, and $p$ values for isolated headache, health complaints, and the combination of both in comparison with no complaints at all-adjusted for sex, grade, and socioeconomic variables

\begin{tabular}{|c|c|c|c|c|c|c|c|c|c|}
\hline \multirow[t]{2}{*}{ Risk factors } & \multicolumn{3}{|c|}{$\begin{array}{l}\text { Isolated headache } \\
\quad(N=188)\end{array}$} & \multicolumn{3}{|c|}{$\begin{array}{l}\text { Any headache }+ \text { any of the } \\
5 \text { health complaints } \\
(N=841)\end{array}$} & \multicolumn{3}{|c|}{$\begin{array}{l}\text { Any of the } 5 \text { health complaints } \\
\text { (excluding headache) } \\
(N=114)^{\mathrm{a}}\end{array}$} \\
\hline & OR & $95 \% \mathrm{Cl}$ & $p^{\mathbf{b}}$ & OR & $95 \% \mathrm{Cl}$ & $p^{\mathbf{b}}$ & OR & $95 \% \mathrm{Cl}$ & $p^{\mathbf{b}}$ \\
\hline \multicolumn{10}{|c|}{ Coffee consumption $(N=1,227)$} \\
\hline None & 1 & \multirow[t]{2}{*}{$0.92-2.68$} & \multirow[t]{2}{*}{0.098} & 1 & \multirow[t]{2}{*}{$1.38-3.53$} & \multirow[t]{2}{*}{0.002} & 1 & \multirow[t]{2}{*}{$1.05-3.64$} & \multirow[t]{2}{*}{0.034} \\
\hline Any & 1.57 & & & 2.21 & & & 1.96 & & \\
\hline \multicolumn{10}{|c|}{ Physical inactivity $(N=1,244)$} \\
\hline No & 1 & \multirow[t]{2}{*}{$0.55-3.12$} & \multirow[t]{2}{*}{0.544} & 1 & \multirow[t]{2}{*}{$1.57-7.15$} & \multirow[t]{2}{*}{0.002} & 1 & \multirow[t]{2}{*}{$1.11-6.77$} & \multirow[t]{2}{*}{0.029} \\
\hline Yes & 1.31 & & & 3.35 & & & 2.74 & & \\
\hline \multicolumn{10}{|c|}{ Alcoholic mixed drinks, cocktails, and hard drinks $(N=1,148)$} \\
\hline None & 1 & \multirow[t]{2}{*}{$0.81-2.56$} & \multirow[t]{2}{*}{0.220} & 1 & \multirow[t]{2}{*}{$1.01-2.77$} & \multirow[t]{2}{*}{0.044} & 1 & \multirow[t]{2}{*}{$0.61-2.33$} & \multirow[t]{2}{*}{0.601} \\
\hline Any & 1.44 & & & 1.68 & & & 1.20 & & \\
\hline \multicolumn{10}{|c|}{ Smoking $(N=1,253)$} \\
\hline No & 1 & \multirow[t]{2}{*}{$0.71-2.87$} & \multirow[t]{2}{*}{0.313} & 1 & \multirow[t]{2}{*}{$1.29-4.38$} & \multirow[t]{2}{*}{0.005} & 1 & \multirow[t]{2}{*}{$0.95-4.77$} & \multirow[t]{2}{*}{0.068} \\
\hline Yes & 1.43 & & & 2.38 & & & 2.13 & & \\
\hline \multicolumn{10}{|c|}{ Chronic stress $(N=1,260)$} \\
\hline No & 1 & \multirow[t]{2}{*}{$0.28-7.43$} & 0.665 & 1 & $2.83-48.36$ & $<0.001$ & 1 & $1.34-29.28$ & 0.020 \\
\hline Yes & 1.44 & & & 11.69 & & & 6.27 & & \\
\hline Muscle pain & iead, $n$ & k, or shoulde & egion $(\Lambda$ & $=1,260)$ & & & & & \\
\hline No & 1 & $0.57-2.48$ & 0.650 & 1 & $4.17-14.85$ & $<0.001$ & 1 & $2.34-11.07$ & $<0.001$ \\
\hline Yes & 1.19 & & & 7.87 & & & 5.09 & & \\
\hline
\end{tabular}

${ }^{a}$ Health complaints include the following: dizziness, abdominal pain, musculoskeletal pains, fatigue syndrome, and/or psychic complaints.

${ }^{\mathrm{b}}$ The $p$ values consider Bonferroni correction for multiple comparisons for each variable. Significant results after Bonferroni correction are shown in bold $(p<0.0083)$.

There are many publications that have addressed comorbidities with headache such as abdominal pain, $4,15-18$ musculoskeletal (back, neck, or shoulder) pains, $4,15,18$ vertigo, $^{16,19}$ sleep problems, ${ }^{15,17,19,20}$ or tiredness. ${ }^{19}$ Our findings are in line with these observations. Interestingly, however, isolated TTH accounted for most of the cases of isolated headache, suggesting that migraine might be more often related to other health complaints than TTH.

The weak associations of chronic stress; muscle pain in the head, neck, or shoulder region; the consumption of coffee or alcoholic mixed drinks; and smoking with isolated headache is mainly a reflection of the weak association between isolated TTH and these risk factors. To our knowledge, the associations between possible risk factors and isolated primary headache (types)-explicitly excluding other health complaints-have not been investigated previously.

\section{Strength and Limitations}

Our study is one of the few population-based studies investigating headache in adolescents focusing on generally healthy persons, conducted in schools and not in a clinical setting. The participation rate was high (94.8\%) and only a small number of questionnaires had to be excluded (11.6\%). The large number of participants made it possible to distinguish between different headache types and perform subgroup analyses.

The headache prevalence is especially high among students aiming at higher education. ${ }^{3}$ The external validity is limited because the participants attending grammar schools in the German city of Munich, Bavaria, and belong to families with a relatively high socioeconomic status.

The classifications of headache types and other health complaints were not validated by a physician's diagnosis but were based according to the responses of the participants in the questionnaire that contained established instruments (criteria of the ICHD-II, complaints list from von Zerssen). Only health complaints that were most frequently described by the participants were included in further analyses. Besides headache, dizziness, and abdominal pain, common health complaints were summarized on the basis of medical or psychological coherence into three different complaint group.

In cross-sectional studies, exposure and disease are recorded at the same time. Hence, only statistical associations can be studied, but no temporal relations. A discussion of further strengths and limitations of the present crosssectional study can be found elsewhere. ${ }^{28,30}$ 


\section{Conclusion}

In adolescents isolated headache appears to be rather the exception than the rule. This pertains particularly to pure migraine and migraine $+\mathrm{TTH}$, suggesting that migraine mainly reflects a prominent symptom within a complex of health complaints related to, for example, stress and other risk factors. This concept is further supported by the observation that risk factors were proved to be nonspecific for isolated TTH, which accounted for the most cases of isolated headache. Only among adolescents presenting a combination of headache and other health complaints significant associations could be seen for almost all analyzed risk factors. Interventions, therefore, should consider a holistic approach focusing not only on headache but also on a broader spectrum of health complaints.

\section{Funding}

This research project was not supported by a specific grant from any funding agency in the public, commercial, or notfor-profit sectors.

\section{Conflict of Interest}

The authors certify that they have no financial interest to disclose.

\section{Acknowledgments}

The authors thank Astrid Blaschek, Michaela Bonfert, Kristina Huß, Christoph Schankin, and Petra Sostak for giving lessons regarding headache in the participating schools and their support in the data collection. They also thank all participants for their time and efforts. They also thank the contact persons and principals of the participating grammar schools in Munich for their support and organization of the data collection.

\section{References}

1 Rasmussen BK. Epidemiology of headache. Cephalalgia 2001; 21(7):774-777

2 Roth-Isigkeit A, Thyen U, Raspe HH, Stöven H, Schmucker P. Reports of pain among German children and adolescents: an epidemiological study. Acta Paediatr 2004;93(2):258-263

3 Fendrich K, Vennemann M, Pfaffenrath V, et al. Headache prevalence among adolescents-the German DMKG headache study. Cephalalgia 2007;27(4):347-354

4 Kröner-Herwig B, Heinrich M, Morris L. Headache in German children and adolescents: a population-based epidemiological study. Cephalalgia 2007;27(6):519-527

5 Heinrich M, Morris L, Kröner-Herwig B. Self-report of headache in children and adolescents in Germany: possibilities and confines of questionnaire data for headache classification. Cephalalgia 2009;29(8):864-872

6 Milde-Busch A, Blaschek A, Borggräfe I, von Kries R, Straube A, Heinen $F$. [Is there an association between the reduced school years in grammar schools and headache and other health complaints in adolescent students?] Klin Padiatr 2010;222(4):255-260

7 Milde-Busch A, Heinrich S, Thomas S, et al. Quality of life in adolescents with headache: results from a population-based survey. Cephalalgia 2010;30(6):713-721
8 Stovner LJ, Andree C. Prevalence of headache in Europe: a review for the Eurolight project. J Headache Pain 2010;11(4):289-299

9 Ozge A, Sasmaz T, Cakmak SE, Kaleagasi H, Siva A. Epidemiologicalbased childhood headache natural history study: after an interval of six years. Cephalalgia 2010;30(6):703-712

10 Laurell K, Larsson B, Eeg-Olofsson O. Prevalence of headache in Swedish schoolchildren, with a focus on tension-type headache. Cephalalgia 2004;24(5):380-388

11 Ellert U, Neuhauser H, Roth-Isigkeit A. [Schmerzen bei Kindern und Jugendlichen in Deutschland: Prävalenz und Inanspruchnahme medizinischer Leistungen. Ergebnisse des Kinder- und Jugendgesundheitssurveys (KiGGS).]. Bundesgesundheitsblatt Gesundheitsforschung Gesundheitsschutz 2007;50(5-6):711-717

12 Lewis DW. Headaches in children and adolescents. Curr Probl Pediatr Adolesc Health Care 2007;37(6):207-246

13 Wöber-Bingöl C, Wöber C, Wagner-Ennsgraber C, et al. IHS criteria and gender: a study on migraine and tension-type headache in children and adolescents. Cephalalgia 1996;16(2):107-112

14 Larsson B, Fichtel A. Headache prevalence and characteristics among school children as assessed by prospective paper diary recordings. J Headache Pain 2012;13(2):129-136

15 Hoftun GB, Romundstad PR, Zwart JA, Rygg M. Chronic idiopathic pain in adolescence-high prevalence and disability: the young HUNT Study 2008. Pain 2011;152(10):2259-2266

16 Hershey AD. Pediatric headache: update on recent research. Headache 2012;52(2):327-332

17 Luntamo T, Sourander A, Rihko M, et al. Psychosocial determinants of headache, abdominal pain, and sleep problems in a community sample of Finnish adolescents. Eur Child Adolesc Psychiatry 2012;21(6):301-313

18 Kujala UM, Taimela S, Viljanen T. Leisure physical activity and various pain symptoms among adolescents. Br J Sports Med 1999;33(5):325-328

19 Laurell K, Larsson B, Eeg-Olofsson O. Headache in schoolchildren: association with other pain, family history and psychosocial factors. Pain 2005;119(1-3):150-158

20 Powers SW, Gilman DK, Hershey AD. Headache and psychological functioning in children and adolescents. Headache 2006;46 (9):1404-1415

21 Roth-Isigkeit A, Thyen U, Stöven H, Schwarzenberger J, Schmucker P. Pain among children and adolescents: restrictions in daily living and triggering factors. Pediatrics 2005;115(2):e152-e162

22 Hagen K, Stovner LJ, Zwart JA. Potentials and pitfalls in analytical headache epidemiological studies-lessons to be learned from the Head-HUNT study. Cephalalgia 2007;27(5):403-413

23 Neut D, Fily A, Cuvellier JC, Vallée L. The prevalence of triggers in paediatric migraine: a questionnaire study in 102 children and adolescents. J Headache Pain 2012;13(1):61-65

24 Björling EA. The momentary relationship between stress and headaches in adolescent girls. Headache 2009;49(8):1186-1197

25 Holzhammer J, Wöber C. [Non-alimentary trigger factors of migraine and tension-type headache]. Schmerz 2006;20(3): 226-237

26 Holzhammer J, Wöber C. [Alimentary trigger factors that provoke migraine and tension-type headache]. Schmerz 2006;20(2): 151-159

27 Wöber C, Holzhammer J, Zeitlhofer J, Wessely P, Wöber-Bingöl C. Trigger factors of migraine and tension-type headache: experience and knowledge of the patients. J Headache Pain 2006;7(4): 188-195

28 Milde-Busch A, Blaschek A, Borggräfe I, Heinen F, Straube A, von Kries R. Associations of diet and lifestyle with headache in highschool students: results from a cross-sectional study. Headache 2010;50(7):1104-1114

29 Milde-Busch A, Blaschek A, Heinen F, et al. Associations between stress and migraine and tension-type headache: results from a school-based study in adolescents from grammar schools in Germany. Cephalalgia 2011;31(7):774-785 
54 Specificity of Risk Factors for Headache in Adolescents

30 Blaschek A, Milde-Busch A, Straube A, et al. Self-reported muscle pain in adolescents with migraine and tension-type headache. Cephalalgia 2012;32(3):241-249

31 Headache Classification Subcommittee, International Headache Society. The International Classification of Headache Disorders, 2nd edition. Cephalalgia 2004;24(Suppl 1):9-160
Lehmann et al.

32 von Zerssen D. Die Beschwerde-Liste. Manual. Weinheim, Germany: Beltz Test Gesellschaft; 1976

33 Schulz P, Schlotz W, Becker P. TICS-Trierer Inventar zum chronischen Stress [Trier Inventory of Chronic Stress]. Manual. Goettingen, Germany: Hogrefe; 2004 